\title{
DMTA studies of the effect of storage time on the curing process of sheet moulding compound
}

\begin{abstract}
The application of the dynamic mechanical thermal analysis (DMTA) test method in the study of the effect of storage time on the curing process of sheet moulding compound (SMC) is discussed. Emphasis is placed on following the curing by the study of storage modulus and loss tangent with storage time. Changes in the storage time showed an increase in the storage modulus (log ENjjuring a room-temperature cure. The loss tangent (tan ŭ) damping peak occurs as the system is driven into the glassy state by the cross-linking reaction. The SMC displayed a room-temperature log ENif 8.5 $\mathrm{Pa}$ which increased to approximately $9 \mathrm{~Pa}$ in the subsequent scan in the DMTA.
\end{abstract}

Keyword: Dynamic mechanical thermal analysis (DMTA); Curing process; Storage time; Sheet moulding compound 